\title{
POLÍticas PÚBLICAS E DESENVOLVIMENTO SOCIAL RURAL
}

IVALDo GeHLEN

\begin{abstract}
Resumo: São analisadas algumas transformações recentes na agropecuária brasileira relacionadas a políticas públicas e/ou sociais, com a finalidade de mostrar que políticas públicas eficientes dispensam políticas sociais compensatórias, abordando a agricultura familiar quanto à sua formação histórica, sua competitividade e qualificação profissional, necessárias para o desenvolvimento sustentável. A reforma agrária também é tratada sob a ótica de uma política pública social.

Palavras-chave: política pública e desenvolvimento rural; reforma agrária e política social; desenvolvimento social rural sustentável.

Abstract: Some recent transformations in the Brazilian agriculture are analyzed and related to public and/or social politics. The intention is to show that efficient public politics refute compensatory social politics. They analyze the familiar agriculture in historical formation, its competition and professional qualification required for the sustainable development. The land reform also is discussed through a prism of social public politics. Key words: public politics and rural development; land reform and social politics; sustainable social rural development.
\end{abstract}

$\mathrm{E}$ ste artigo analisa algumas transformações recentes na agropecuária brasileira que têm correspondências com políticas públicas e/ou sociais, priorizando a abordagem sobre a agricultura familiar como um modo de vida e de produção centrado no trabalho não assalariado e na organização da unidade de produção, determinada pelas estratégias de qualidade de vida e de eficiência do uso do espaço e das tecnologias e pela constituição de sociedades locais estruturadas e integradas por valores de cidadania e identidade. O objetivo é mostrar que políticas públicas eficientes dispensam políticas sociais compensatórias, recomendadas para situações emergenciais e de risco ou de superação de legados históricos específicos, como, por exemplo, incluir segmentos sociais não contemplados historicamente pelas políticas de desenvolvimento. Estas situações assistidas devem ser transitórias, com cronograma definido, e substituídas por políticas públicas que podem estar assentadas no social. No meio rural, há evidências que confirmam esta convicção. As partes em que se divide este artigo correspondem a aspectos específicos de políticas públicas/sociais do meio rural.

\section{COMPETITIVIDADE E PROFISSIONALIZAÇÃO NÃO SUPERAM AS DESIGUALDADES SOCIAIS NO MEIO RURAL}

Um novo olhar sobre o rural complexificado resgata o cidadão crescentemente participativo não só nas suas questões (local), mas também nas nacionais e internacionais, e em processo de diferenciação e profissionalização.

Dois aspectos emergem com clareza desse olhar: as tendências que apontam para transformações profundas do rural; e o dinamismo social expresso nas lutas por interesses específicos e pela construção de referências novas, junto e para a sociedade local, nacional e mesmo global. Neste sentido, as políticas de tipo participativas e dirigidas para segmentos específicos (como é o caso do Pronaf), embora apontem para mudanças, tendem a fortalecer os que apresentam racionalidade "moderna" e centrada na ética do trabalho e da competitividade, apropriando-se das melhores chances. Não havendo igualdade de chances nas oportunidades que se oferecem, verifica-se que as políticas públicas convencionais (tipo crédito agrí- 
cola, por exemplo, ou estímulo à formação de cooperativas) não superam a discriminação e a desigualdade entre uns e outros, como caboclos, indígenas, negros dos quilombos, por exemplo. Estes são portadores de racionalidades centradas em outros valores éticos sobre a reprodução socioeconômica e as relações sociais e com o meio natural. Nos exemplos citados, priorizam-se os valores de convívio e de sustentabilidade em detrimento aos de competitividade.

Mesmo sob a aparência da igualdade (Dahrendorf, 1992), as chances de sucesso são diferentes e beneficiam os que detêm poder de decisão sobre as condições necessárias para aproveitar as oportunidades. Por isso, políticas públicas com interesse social devem beneficiar de forma diversificada os que possuem necessidades diferenciadas, no sentido de propiciar as condições para superação das desigualdades, sendo que, aos poucos, essa "vantagem" em benefício de grupos sociais identificados deve perder vigência, para converter-se numa política pública igualitária. O tema das quotas, em moda no discurso de militantes e de políticos, se enquadra nesta perspectiva.

No caso da agricultura, as políticas públicas recentes de financiamento às atividades rurais, a descentralização através dos Conselhos Municipais, especialmente os de Desenvolvimento Rural, o financiamento da habitação, etc. estão propiciando a emergência de novos atores sociais, principalmente a figura do agricultor familiar profissionalizado e do granjeiro. ${ }^{1}$ A profissionalização inclui o discurso sobre competitividade como referência ideológica e mecanismo econômico, interpondo produtor e consumidor como duas faces de uma realidade.

As transformações operadas por estes processos geram impactos que induzem a reelaboração de conceitos, como o de identidade sociocultural, que inclui a noção e o "lugar" do trabalho, e o de cidadania, que inclui as relações de trabalho e com o meio ambiente. Tal processo introduz/altera, na ótica dos produtores, os conceitos de trabalho e de competitividade nos seus aspectos de qualidade e de produtividade, cujos impactos interferem na reelaboração da identidade socioprofissional, principalmente entre os chamados modernizados pelas tecnologias que usam ou pelas vinculações com a indústria e o mercado de produtos in natura. Estas transformações, entretanto, não se universalizam e as políticas têm se mostrado insuficientes para resolver os problemas dos "esquecidos" históricos (caboclos, indígenas, quilombolas) e de cerca de $12 \%$ da população do meio rural brasileiro que vive em condições abaixo da chamada "linha de pobreza".
Tendo por base a formação da sociedade brasileira, sobretudo a sulina, constata-se que existe correlação entre desigualdades socioeconômicas e as identidades a que pertencem a maioria dos grupos "excluídos" dos processos civilizatórios que colonizaram os territórios. Uma alternativa de superação ou diminuição dessas desigualdades é a qualificação para o exercício eficiente das atividades reconhecidas como importantes pela sociedade. É o processo de profissionalização, que, mesmo contraditória, pode ser uma das alternativas para garantir cidadania e afirmar identidades socioculturais. A afirmação referencia-se num aparente consenso, fundado na noção de competitividade. Porém, esta consensualidade reintroduz a questão da centralidade do trabalho, na sua perspectiva de competitividade, porém flexível, pois inclui, além da produtividade do trabalho, a qualidade de vida do trabalhador, a qualidade do produto e do meio ambiente. Esse consenso transfere o sucesso de uns ou insucesso de outros para a esfera privada ou individual, recriando o indivíduo competitivo e interativo.

O trabalho, no significado moderno, exige uma perícia, ou qualificação: na indústria, quanto mais moderno, a qualificação exigida é mais específica, restrita (embora estejam ocorrendo mudanças ainda pouco conhecidas); na atividade agrícola familiar, quanto mais moderno, mais abrangente e complexa a qualificação exigida, pois "se há alguma coisa que distancia a agricultura do imaginário industrial, é bem esta; à desqualificação do trabalho do operário pode-se opor o aumento das exigências de qualificação do trabalho agrícola, cada vez mais complexo" (Jean, 1994:55). Para ser eficiente na agricultura moderna, é preciso renunciar a saberes tradicionais e apropriarse de outros, levando à perda do controle do processo em sua totalidade, criando dependência do(s) técnico(s). É através da relação mediada pelos técnicos que se produzem a dominação e a expropriação. No contexto agroindustrial, a conflitualidade pelo saber é importante, porque mexe com a identidade dos agricultores e transfere para a relação agricultor/técnico o conflito agricultor/agroindústria.

Estas mudanças põem em risco as condições de reprodutibilidade social, econômica, política e cultural dos produtores familiares agropecuários. A recomposição seletiva referencia-se na noção de competitividade, tanto entre os modernizados e/ou em transição, quanto entre os tradicionais. Gera-se assim um conflito conceitual entre a racionalidade competitiva das agroindústrias, que priorizam a produtividade, e a dos produtores que priorizam 
sua reprodução social e a sustentabilidade ambiental onde vivem.

Para serem eficientes na agricultura moderna, os produtores necessitam renunciar parte de seu saber tradicional e se apropriar de um novo saber, constituindo-se num processo de (re)profissionalização. Tal processo ocorre no ritmo das exigências do mercado e não no da maturação de um aprendizado ou do saber reelaborado, levando muitas vezes à perda do saber técnico herdado.

$\mathrm{O}$ reconhecimento de que, neste processo, ocorre a exclusão de parte dos produtores deve-se a fatores ligados à imposição de condições tecnológicas e de valores, símbolos e hábitos racionais que alteram os tradicionais. Este processo, com dimensões objetivas e subjetivas, se opera, ao mesmo tempo, pela exaltação da competitividade do mercado e pela adoção de identidade profissional.

\section{FORMAÇÃO DA AGRICULTURA FAMILIAR MODERNA E DOS EXCLUÍDOS DO MUNDO RURAL}

A afirmação nacional manteve-se vinculada ao conceito de civilização, agora com o nome de modernização, que impôs um cidadão construído racionalmente sobre a noção de indivíduo desenvolvido (civilizado) pela ética do trabalho, que se sobrepôs ao de identidade sociocultural. Esta concepção dominante "liberou" os colonizadores e colonos imigrantes para civilizar (pela substituição) os modelos autóctones.

Durante a consolidação da modernização do aparato estatal e da política a partir da Revolução de 1930, alimentou-se um grande debate sobre a expansão da fronteira agrícola e a integração nacional como política de desenvolvimento. Tal debate, especialmente no período de 1930 a 1945, comparou as diversas "forças de trabalho" disponíveis: os nacionais ou caboclos, os afros e os europeus (imigrantes do final do século XIX ou início do XX). Sendo o trabalho produtivo o determinante na concepção de desenvolvimento de então, a conclusão foi de que a ocupação dos espaços "vazios" teria melhor sucesso com os imigrantes que preenchiam as condições "adequadas à plena realização do projeto nacional (...) do progresso econômico do Brasil" (Vainer; Azevedo, s.d.:5). O argumento central, portanto, para incluir ou excluir grupos sociais ou identidades socioculturais nas políticas de desenvolvimento era econômico, representado pelo trabalho produtivo. A qualificação dos nacionais e dos de origem afro seria difícil, custosa e demorada, pois possuíam modos ou hábitos de vida considerados pouco metódicos e comportamentos incertos em relação ao conceito dominante do trabalho. Esta ausência de disciplina metódica e de regularidade no trabalho são argumentos constantes até hoje.

A politização do conceito de igualdade pela burguesia atribuiu positividade ao trabalho, visto como único responsável para o progresso e justificado socialmente pela noção de bem-comum, em que todos seriam beneficiários dos resultados do trabalho. Seus ordenadores criaram mecanismos formais para se apropriarem privilegiadamente desses resultados, constituindo-se em classe dominante e, com isso, impondo seus hábitos e modo de vida como referência de civilização. Neste contexto o incluído é o civilizado, o moderno.

Daí decorre que as políticas públicas de então eram para estimular o trabalho produtivo de mercadorias, garantir produtividade. O progresso ou desenvolvimento rural significava substituir o selvagem (fauna e flora) e o nativo (indígenas e caboclos) pelo culturalizado e pelo mercado. “(...) a lógica econômica do caboclo não é uma lógica mercantil. Mesmo que ele continue como produtor parcial de valores de troca - e um produtor mercantil, que se insere de certa forma na divisão social do trabalho - sua existência econômica se baseia acima de tudo sobre o usufruto imediato dos bens que possui" (Fase, 1979:95). Desde então, construiu-se a ideologia cultural de valorização do importado/exportado e desqualificação do nacional, dos produtos, da mão-de-obra, inclusive científica, e dos valores. Na agropecuária esta ideologia teve efeitos profundos, como, por exemplo, os preços dos produtos e sobretudo o não reconhecimento da cidadania plena dos agricultores que produziam preferencialmente para o mercado interno. Foi somente com a Constituição de 1988 que se reconheceu a equiparação e em muitos aspectos, como da mulher trabalhadora rural, recentemente.

Tal processo se deu muitas vezes à custa da subordinação sociocultural e, por vezes, com a destruição das identidades que resistiam à subordinação imposta através do trabalho e do novo sistema de valores "nacionais", gerando, não raro, conflitos que persistem até hoje. Em nome da civilização procurou-se justificar o genocídio dos indígenas, o menosprezo aos caboclos na América, a perseguição aos ciganos na Europa e a escravidão dos negros da África.

A modernização reverteu uma tradição milenar dos agricultores, impondo o tempo como disciplinador do trabalho produtivo e como referência valorativa de moderno. A imposição da produtividade (relação idealizada: tra- 
balho/tecnologia/produção) como objetivo do trabalho produtivo desestruturou saberes técnicos acumulados experimentalmente. Seus efeitos foram profundos, indeléveis e diferenciados sobre as diversas classes e/ou grupos sociais específicos. Redefiniram-se identidades profissionais e socioculturais. Produziram-se exclusão e pobreza devido ao não ou ao pouco trabalho e inclusão e riqueza graças ao "muito" trabalho.

A atividade econômica tradicional do caboclo é a agricultura de subsistência, por ele considerada meio de reprodução biológica, social e cultural, mas que tem fraco poder de inserção econômica e política na sociedade global. Historicamente, o caboclo permaneceu fracamente vinculado aos mercados - seu contato foi apenas o necessário em negócios eventuais - e isolado pela ausência de vias de comunicação, assim como pela estigmatização social. Seu significado econômico (mesmo quando residindo próximo de cidades) nunca foi reconhecido e até hoje as portas de acesso aos mercados, aos bens culturais e aos poderes de decisão continuam fechadas para ele. Isto torna difícil, senão impossível, transformar-se em agricultor familiar empresarial, moderno, pois "os caboclos têm muitas vezes uma história de agricultor sem terra itinerante e de submissão pessoal aos proprietários fundiários, que contrasta com o estatuto originário da pequena propriedade parcelária. Isso induziu muitos autores a opor de forma dicotômica - e muitas vezes negativa - aos comportamentos e à cultura de colonos imigrantes. Partindo de uma constatação correta, os autores em questão têm, no entanto, esquecido ao menos três fatores que intervêm na formação dessas categorias sociais: a) a inegabilidade de oportunidades que dispunham os caboclos e os imigrantes, bem como tentativas dos primeiros para evitar a marginalização que a sociedade lhes impunha; b) o processo de aproximação entre caboclos e colonos, encetado ao longo do tempo; c) o efeito dessa aproximação, a saber, a gênese, entre os antigos e os novos caboclos, de um ideal de pequenos produtores parcelários não se verifica senão na sua versão mais tradicional: economia familiar, produção de subsistência, etc." (Gaiger, 1991:75).

Por estas razões, as políticas sociais continuaram vinculadas ao sucesso na reprodução dos modelos racionais conhecidos e dominantes no Ocidente.

A imposição moderna de trabalho aprofunda a exclusão de quem não introjetou sua centralidade. A base associativa do trabalho é a família "ampliada", inclusiva do compadrio. Seu sistema de produção e organização do trabalho orienta-se pela lógica da sobrevivência. Desenvolveu um sistema, integrando extrativismo, pecuária e agricultura, conhecido como Faxinal. ${ }^{2}$

O caboclo, na sua trajetória de pioneiro/nômade, enfrentou-se com os índios, os fazendeiros e os colonos, porém, nunca conseguiu transformar suas possessões em propriedades. O depoimento de Zanatta ${ }^{3}$ descreve a rejeição do caboclo na região de Planalto, do Rio Grande do Sul, onde viveu sua infância com os pais donos de uma serraria:

“as terras pertenciam ao Estado (...) alguns caboclos que lá residiam queriam comprar, mas não concediam a terra facilmente a essa gente. A preferência era sempre dos colonos que chegavam" (Entrevista ao autor em 15/04/1988).

Isto os obrigava a partir novamente. Salvo raras exceções, ${ }^{4}$ eles não fizeram parte de políticas oficiais de colonização.

As políticas de tipo desenvolvimentistas predominantes na agropecuária brasileira estimulam a violência, atribuindo-lhe, por vezes, sentido de crueldade para a maioria que pertence às categorias subordinadas, como a agressão exterminadora contra os indígenas, os tratamentos violentos infligidos aos escravos afros e prolongados no destrato aos quilombolas, olvidados legal e socialmente das políticas de inclusão social. ${ }^{5}$ Os caboclos e parte do colonato do café (em São Paulo) passam por processo semelhante de exclusão violenta, de expulsões de seus territórios, de recusa da cidadania, semelhante aos semterra de hoje.

A modernização e a afirmação nacional (Independência, República, Revolução de 1930, Ditadura Militar, redemocratização na década de 80) mantiveram-se vinculadas ao conceito de civilização, impondo uma noção de cidadania relacionada a uma forma social, considerada desenvolvida (civilizada), sobrepondo-se à de identidade sociocultural.

É a partir das lutas sociais de resistência, de reivindicações ou de produção de políticas para o setor que se desenvolve um conceito positivo da atividade rural, expresso pela auto-estima crescente e pela afirmação social da agricultura familiar. Aos poucos recriaram-se o discurso e uma linguagem favorável a esta forma de agricultura, com conceito definido. $\mathrm{O}$ agricultor familiar passou a recusar ser identificado por termos com os quais não se identificava, tais como camponês colono ou trabalhador rural. Em alguns lugares, retomou-se o sentido original do termo colono por razões mercadológicas, especialmente tu- 
rísticas. Em outros lugares, como na região produtora de soja, no Sul, os descendentes de imigrantes europeus abandonam o termo e o substituem por familiar, empresário agrícola, ou pela identificação profissional: fumicultor, sojicultor, avicultor, etc.

A agricultura familiar passou a ser vista como um sistema de produção específico e particular, com grande capacidade de adaptação. Esse discurso, construído também pelo engajamento das universidades, generalizou-se através de pesquisadores, técnicos e lideranças apoiados pela mídia e instituições diversas, como as igrejas, por exemplo. O modelo familiar, bem estruturado, com políticas adequadas, é econômica e socialmente eficiente, sensível às questões ambientais e, por isso, se afirma crescentemente como sustentável ou durável. As contestações à generalização desse modelo, principalmente nas décadas de 60 e 70, representavam uma defesa do latifúndio e da oligarquia ou uma postura ideológica de defesa do comunitarismo empresarial (empresas coletivizadas). Estas críticas foram superadas pela sua eficácia econômica e social inquestionáveis, nos países onde o modelo possui expressividade.

Os dados da Tabela 1, que seleciona alguns Estados do Centro-Sul do Brasil, mostram que, mesmo possuindo um Índice de Desenvolvimento Humano (IDH) relativamente elevado (o máximo é 1,0 ), a terra continua fortemente concentrada, segundo expressa o índice de Gini (1,0 seria concentração máxima).

A ocupação da População Economicamente Ativa PEA em atividades agropecuárias tende a ser mais elevada do que o percentual de residentes no espaço rural, pois cresce o número dos que se dedicam a este tipo de atividade, porém moram em cidades.

Os dados da Tabela 1 mostram a forte representatividade dos estabelecimentos familiares e apontam para a necessidade de políticas específicas, já inauguradas em 1996, através do Programa Nacional de Fortalecimento da Agricultura Familiar - Pronaf. ${ }^{6}$ Iniciou-se recentemente uma política habitacional para este segmento social. Havia financiamento para alojar animais, porém, para residências não eram disponibilizados. As políticas públicas para os agricultores familiares, inclusive o Pronaf, resultaram de reivindicações e pressões de suas organizações e representações de classe e de lutas sociais, durante muitos anos. A concepção e execução do Pronaf contemplam a participação de organizações dos agricultores. Estas mudanças expressam uma nova visão do significado e do papel da agricultura familiar no Brasil, sobretudo para o desenvolvimento sustentável.

\section{REFORMA AGRÁRIA: POLÍTICA PÚBLICA OU POLÍTICA SOCIAL?}

A PEA brasileira ocupada em atividades rurais (cerca de $22 \%$ ) é relativamente alta em comparação com países industrializados da Europa e América do Norte, que ocupam entre $2 \%$ e $5 \%$. Preservar este índice não parece uma idéia distorcida, se o desenvolvimento pretendido é sustentado na qualidade de vida e na manutenção de oportunidades. Nos últimos anos, a valorização das atividades rurais deu-se, principalmente, por meio das lutas sociais, especialmente aquelas pela remuneração do trabalho (pre-

TABELA 1

IDH, População Rural, Índice de Gini e Representatividade da Agricultura Estados Selecionados - 1996-2000

\begin{tabular}{|c|c|c|c|c|c|}
\hline \multirow{2}{*}{$\begin{array}{l}\text { Estados } \\
\text { Selecionados }\end{array}$} & \multirow{2}{*}{$\begin{array}{c}\text { IDH } \\
(1996)\end{array}$} & \multirow{2}{*}{$\begin{array}{l}\text { População Rural } \\
\text { (2000) (\%) }\end{array}$} & \multirow{2}{*}{$\begin{array}{l}\text { Índice Gini } \\
\text { Terra (1996) }\end{array}$} & \multicolumn{2}{|c|}{ Agricultura Familiar (1996) (\%) } \\
\hline & & & & Estabelecimentos & Área \\
\hline Brasil & 0,830 & 18,75 & 0,856 & 85,2 & 30,5 \\
\hline Rio Grande do Sul & 0,869 & 18,75 & 0,762 & 91,7 & 40,9 \\
\hline Distrito Federal & 0,869 & 4,34 & 0,801 & 25,8 & 8,0 \\
\hline Santa Catarina & 0,863 & 21,25 & 0,671 & 94,3 & 60,0 \\
\hline São Paulo & 0,868 & 6,59 & 0,758 & 68,9 & 24,5 \\
\hline Paraná & 0,847 & 18,58 & 0,741 & 86,9 & 41,9 \\
\hline
\end{tabular}

Fonte: Gasques; Conceição (2001:489); PNUD/Ipea/FJJ/IBGE (1998); Guanziroli; Cardim (2000); IBGE, Censo Demográfico (2000) e Agropecuário (1995-96). 
ços dos produtos agrícolas), a das mulheres trabalhadoras rurais que ampliam sua cidadania através da mudança de seu estatuto de donas-de-casa para trabalhadoras rurais, alterando com isto o conceito de trabalho, até então exclusivamente vinculado à produção de mercadorias, e a da luta pela terra, visando continuar a realização da reforma agrária. $\mathrm{O}$ debate sobre reforma agrária induz a uma perspectiva de valorização das atividades rurais, priorização do social, eliminação dos focos dos conservadorismos econômicos e políticos, representados pelo latifúndio patrimonialista, e implantação do desenvolvimento sustentável.

A organização e mobilização dos destituídos da posse ou propriedade fundiária, para reverter o quadro de sua concentração entre proprietários que a mantém improdutiva, amplia-se à medida que eles se convencem do direito de acesso às atividades que gozam de reconhecimento social, no caso, a agricultura familiar. Este reconhecimento dá visibilidade e reconstrói no imaginário coletivo o "capital simbólico" que os move na conquista de seus interesses, de forma a se associarem em organizações como estratégia de ação social. Os movimentos sociais lutam por inclusão econômica e social através do acesso aos meios de trabalho e de vida, entre os quais o de reforma agrária, e se fortalecem com a não implementação das políticas que reivindicam, convivendo assim com um "estado permanente" de tensão e conflitos, que lhes dão visibilidade e legitimidade social, fortalecendo seu poder de pressão, de barganha e de organização. É o que testemunha uma liderança da luta pela terra, para quem "os fazendeiros não aceitam que os trabalhadores se organizem (em MST, Sindicatos, etc.) e não aceitam que participem ativamente da política (...) Nós temos hoje, no Estado [Espírito Santo], 50 novos líderes, surgidos apesar das ameaças e das perseguições dos latifundiários"? ${ }^{7}$

A luta pela terra revela contradições que despertam a consciência social sobre a injustiça da distribuição e uso da terra e estimulam a organização dos envolvidos, qualificando-os para resistir às pressões dos proprietários latifundiários e pressionar o governo para execução de políticas de assentamentos. O formalismo do judiciário e da repressão policial, em geral inibidores das transformações, tem se mostrado crescentemente menos eficaz ou mais susceptível a uma visão social, em relação à reforma agrária. Isto contribui para "multiplicidade das vias de transformação no campo brasileiro" (Garcia, 2003:169), ${ }^{8}$ ampliando as iniciativas de transformação.
Foi a partir da visibilidade dada pela emergência das lutas que a questão agrária brasileira passou a ser analisada como complexa, produtora de diferenças e de desigualdades sociais tão ou mais expressivas quanto as da sociedade geral. A discussão sobre a necessidade da reforma agrária e seu modelo, na década de 50 até meados da de 60 , retomada no final dos anos 70 , mobilizou um conjunto de forças sociais e acirrou o confronto de interesses como, provavelmente, não tenha ocorrido com nenhuma outra política pública, salvo a Constituinte (1988), nas décadas recentes. Ao se levantar a questão da necessidade e do modelo, as lupas da mídia, de pesquisadores e de militantes se voltaram para esse "mundo" pouco conhecido socialmente. Quem são os sem-terra? Quem são os latifundiários? O que e como se produz no rural brasileiro? Estas perguntas serviram de mote para desvelar esta realidade com suas diferenças e potencialidades. A opção por uma política de reforma agrária que privilegia o modelo familiar foi uma conquista da "esquerda", que embutiu a prioridade do social nesta política. Ganhou na luta simbólica e ganhou inclusive na luta política, porque o próprio governo, que titubeava em relação à reforma agrária, assumiu que sua implantação reproduziria o modelo familiar.

A Carta de Punta del Este ${ }^{9}$ apregoava a reforma agrária para o desenvolvimento da América Latina, que estava centrado em duas razões mestras: a econômica e a política. Era preciso modernizar a agricultura pela eliminação do latifúndio improdutivo, transformando-o em fazenda, em propriedade agrícola moderna. A estratégia era desapropriar as terras e distribuí-las para quem assumisse o "novo" projeto de produzir de forma intensiva para abastecer o mercado interno e para exportar. Na retomada dos assentamentos em 1979, essa argumentação continuava no discurso, porém, agregava-se a dimensão social, no sentido de beneficiar os que não tinham trabalho, não tinham terra, atendendo à demanda de produção, sobretudo de alimentos baratos. A modernização agrícola já estava em fase adiantada, diminuindo a força deste argumento para justificar a reforma agrária.

Ao longo das últimas décadas, o debate e as práticas reelaboraram o conceito e o conteúdo da reforma agrária à "margem" do governo, na "periferia" do poder político e dos interesses do capitalismo, menosprezando a Carta dos Presidentes de Punta del Este. Passou a ser pensada e apresentada como não capitalista. A burguesia brasileira se recusou a desempenhar o papel de produzir um projeto e executar essa reforma, desdenhando essa responsabili- 
dade e não assumindo, enquanto classe social, essa questão como sendo central entre as demandas do povo brasileiro. No bojo dessa inoperância, o novo conceito vai se construindo e ampliando. Permanecem seu caráter antilatifundiário e sua necessidade para ampliar a produção de alimentos e de riquezas, mas agregam-se os argumentos de combate à pobreza no campo e na cidade e, mais recentemente, ainda reticente, de respeito ao meio ambiente. Com isso a bandeira da reforma agrária é retirada das mãos da burguesia e dos partidos políticos e apropriada pelos movimentos sociais e organizações ou instituições de apoio, enfim pela sociedade civil. Essa mudança de comando para a sociedade civil foi a novidade introduzida no Brasil no conceito de reforma agrária, diferentemente dos demais países que a realizaram.

A reforma agrária, por essência, é política pública com forte impacto social, sem diminuir os argumentos econômicos de aumentar a produção e de inclusão de parcela da população no circuito do mercado de produtores e de consumidores. O latifundiário é consumidor de recursos públicos, via subsídios ou endividamento e com baixo índice de retorno. O desenvolvimento local e regional sofre impacto positivo e diversificado com esta política, como mostra ampla literatura. ${ }^{10} \mathrm{O}$ argumento do desenvolvimento local é aceito pela sociedade como justificativa para o uso de recursos públicos em prol de políticas específicas e temporárias. Nesta perspectiva do desenvolvimento econômico, combinado com a diminuição da pobreza pela oferta de postos de trabalho e pela dinamização do desenvolvimento local, a reforma agrária é legitimada porque responde a interesses gerais, não apenas dos assentados.

Uma correta política de reforma agrária deve propor o uso de tecnologias sustentáveis em relação ao ambiente natural, pouco presente até o momento, pois implica compromissos com opções tecnológicas alternativas e significa estruturar a rede ou o sistema de distribuição dos produtos, (re)organizando o mercado. Os consumidores das cidades têm manifestado disposição de aceitar um custo maior com a reforma agrária, se tiverem certeza da qualidade dos produtos e da sustentabilidade, inclusive a ambiental, dos assentamentos.

A análise das lutas sociais, dos sonhos, por vezes utópicos, expressos nas pautas de reivindicações, mostra um "novo" social em gestação, que se manifesta pelas dinâmicas das organizações, pelas formas de solidariedade e pelo engajamento político. A reforma agrária, nesta perspectiva, é uma resposta em forma de política pública estratégica, que se insere na concepção de um projeto de sociedade. Seu conteúdo se legitima, sobretudo, pelo seu caráter social, político, ambiental e econômico. Uma correta política de reforma agrária não precisa ser complementada por políticas sociais compensatórias - em algumas situações podem ser necessárias, no curto prazo e emergencialmente, políticas assistenciais -, pois ela é social na sua essência. Este novo enfoque se sustenta também na noção de que o desenvolvimento valoriza os interesses da sociedade, em geral, e dos locais, de forma particular, priorizando a vida, enquanto qualidade e durabilidade, em detrimento ao crescimento ou acumulação econômica.

\section{DILEMAS PARA POLÍTICAS PÚBLICAS DE DESENVOLVIMENTO RURAL SUSTENTÁVEL}

No século XIX, a contestação ao modelo colonial (monoculturista, exportador e tecnologicamente tradicional) se fazia pela busca de uma alternativa global do modelo de sociedade, incluindo-se aí a estrutura fundiária, ou seja, da posse e uso da terra. No entanto, os compromissos deixados pelo regime imperial - conservador e garantidor dos privilégios das oligarquias agrárias inviabilizaram as transformações necessárias para a pretendida modernização e construção da sociedade nacional "autônoma". Posteriormente, a República obteve pouco sucesso na superação desse modelo. A construção do projeto Brasil, economicamente forte e socialmente justo, foi protelado e com ele foram adiadas as reformas, entre elas a agrária, porque incluía a democratização fundiária. Em razão disso, ou seja, de expectativas não realizadas, instaurou-se um processo de frustrações e estigmatizações.

O estigma ${ }^{11}$ (Goffman, 1988) atribuído aos excluídos transforma as vítimas nos primeiros responsáveis pelo seu fracasso. A cultura dominante estabelece os atributos, que assumem normatividade de conduta "consensuais", estabelecendo categorias e hierarquias sociais. Estigmatizando grupos sociais, reafirma-se a ordem social imposta pela responsabilização dos excluídos, pela própria condição e pela incapacidade de incluir-se através dos mecanismos convencionais, especialmente o trabalho. As diferenças sociais são apresentadas como naturais, invertendo a percepção do real.

Nesta perspectiva, qualquer política de transformações estruturais no rural constitui uma interface perturbadora de interesses oligárquicos e geradora de profundas transformações nas relações, alianças, conflitos e contradições, tanto na sociedade local quanto na regional e/ou nacio- 
nal. A desestruturação da fonte do poder patrimonialista/ latifundiário instaura confrontos, disputas, violências, enfim conflitos sociais, crescentemente cotidianos. As transformações estruturais geram novas referências valorativas, éticas e de convívio social, recriando sonhos e idealizações do futuro. Esta é a dimensão cultural estratégica de políticas públicas que respeitem o social construído historicamente e que se inspirem na valorização das diferenças e não no seu aniquilamento. Social este que se manifesta pela criatividade de organização, pelas novas formas de solidariedade e pela politização das lutas. A reforma agrária vista nesta perspectiva não é uma medida pontual e nem concerne somente aos interesses exclusivos dos sem-terra, mas, ao contrário, se insere na concepção de um projeto de sociedade.

No Brasil a noção de desenvolvimento local se fortalece através de políticas públicas, de organizações locais formais e informais. Sua dinâmica se deve às metodologias de indução do desenvolvimento econômico e sustentável. O chamado DLIS ${ }^{12}$ - Desenvolvimento Local Integrado e Sustentável - prevê a metodologia participativa como força motriz do sucesso das iniciativas. O desenvolvimento local resulta, sobretudo, da mobilização de recursos. Nesta dimensão, o local é um território natural, porém socialmente construído, delimitado por um conjunto complexo de variáveis e indicadores: clima, fauna, flora, modo de vida, identidades, política, etc., que no conjunto atribuem especificidades. Pode-se definir o desenvolvimento local como as dinâmicas social, econômica, política e cultural num território demarcado por especificidades que induzem mudanças qualitativas naquele espaço.

O desenvolvimento local resulta da potencialização da participação dos beneficiários, através de iniciativas comunitárias, promovendo parcerias com o Estado (nos três níveis) e com empresas privadas. Fundamenta-se, sobretudo, nas potencialidades dos recursos humanos, institucionais e naturais que compõem o patrimônio sociocultural ou também chamado capital social. Parte-se de diagnósticos para identificar potencialidades e gargalos até a formulação de uma proposta global de desenvolvimento, como antecipação do futuro a ser atingido e as escolhas de estratégias operacionalizadas em planos integrados de desenvolvimento. Este é o cenário em que políticas públicas de desenvolvimento se fundem com o social para valorizar as diferenças e conquistar qualidade de vida e ambientes sustentáveis.

Uma estratégia que está sendo apropriada para burlar a exclusão social, no meio rural, é a incorporação de re- cursos tecnológicos de baixo custo, por meio de ações associativas ou comunitárias que otimizam os ganhos, através da compra e venda em comum, da pressão para barganhar melhores preços ou para a criação de sistemas condominiais de coleta e transporte e, em alguns casos, industrialização dos produtos. Porém, esta estratégia somente terá sucesso se ancorada em políticas públicas de apoio financeiro e técnico, de qualificação profissional e de infra-estrutura.

As experiências revelam a crescente complexidade no que se refere às políticas públicas, em que instituições diversas, com responsabilidade social, se associam para cumprir um papel até recentemente monopólio do Estado. Nestes casos, parece consolidar-se a simbiose entre política pública e política social, uma sendo a outra e vice-versa.

\section{NOTAS}

1. Granjeiro, termo usado no sul do Brasil, refere-se a produtores agropecuários, com presença maior na agricultura cerealeira, muitos ascendentes da condição de agricultores familiares, usuários de área "média" (entre 100 e 300 ha), em geral qualificado e modernizado. Vive da atividade (sua especulação se assenta nas oportunidades tecnológicas e de produtos), tem sensibilidade ambiental e social no trato com a sociedade local e com os empregados e constitui grupo social em ascensão.

2. Exemplo de sistema caboclo é o Faxinal, muito comum no Alto Uruguai, do Rio Grande do Sul, no oeste de Santa Catarina e no Paraná. O Faxinal é uma forma de organizar a comunidade. O sistema de Faxinal integra: "extrativismo, pecuária e agricultura, conhecido como faxinal, combinado com a técnica do pousio. Aos poucos também expandem a atividade suinícola (pelo sistema conhecido como de 'roças de mato' ou de 'clareira'), a atividade pecuária do leite e a ampliação do extrativismo da madeira e da erva mate" (Gehlen, 1998:129). Em conseqüência os caboclos (ou "nacionais" ou "pêlo duro"), considerados intrusos, eram expulsos das terras de mato (Martini, 1993).

3. Edvino Zanatta, agricultor familiar, dono de moinho familiar de cereais, filho de imigrantes italianos no Rio Grande do Sul, membro e atuante da Comissão Pastoral da Terra (da Igreja Católica) e residente em Campo Erê (Santa Catarina).

4. A inclusão dos nacionais na política de colonização do governo do Rio Grande do Sul, no início do século XX, deu-se dentro do polêmico espírito republicano de promover um desenvolvimento nacionalista com os brasileiros, pressupondo que a presença massiva de estrangeiros pudesse ser um perigo para a soberania nacional.

5. Somente em 1988 a Constituição reconheceu a legítima reivindicação de reconhecimento das terras ocupadas pelos quilombolas.

6. O Pronaf foi implantado a partir de 1996 e há uma análise detalhada em Gasques e Conceição (2001).

7. Testemunho do agricultor João Ramalho. Jornal dos Trabalhadores Rurais Sem-Terra, n.80, p.13, fev. 1989.

8. Afrânio Garcia (2003) mostra, neste artigo, entre outros assuntos, as origens sociais do movimento dos sem terra.

9. Em 1961, reuniram-se, na cidade uruguaia de Punta del Este, os presidentes dos países americanos (OEA), sendo que o documento 
conjunto final defendia a reforma agrária como prioridade para a América Latina.

10. O estudo mais recente e amplamente fundamentado sobre os impactos locais e regionais dos assentamentos é o de Leite et al. (2004).

11. O estigma visa tornar o processo social excludente e aparentar as diferenças sociais como naturais, invertendo a percepção do real e responsabilizando os estigmatizados pela sua exclusão, como resultado da incapacidade de adaptação ao meio ou ao trabalho (no caso dos caboclos). Visa, enfim, evitar a negação do modelo social que lhes é estruturalmente excludente (Goffman, 1988).

12. O DLIS (Desenvolvimento Local Integrado e Sustentável) é um projeto integrante do Programa AED (Agência de Educação para o Desenvolvimento) que é público, fundado em 2001. Fazem parte o Sebrae, o PNUD, a Unesco, o Projeto DLIS e a Arca (Sociedade do Conhecimento). Disponível em:

$<$ http://www.aed.org.br/frame_geral.php?pagina_principal= sobre_tema/index.php?cont=sobre_tema_dlis $>$, no portal:

$<$ http://www.dlis.org.br/>. Acesso em: 12 abr. 2004.

\section{REFERÊNCIAS BIBLIOGRÁFICAS}

AGUIAR, R.C. de. Abrindo o pacote tecnológico. São Paulo: Polis/ CNPq, 1986.

BANDECCHI, B. Origem do latifúndio no Brasil. Cadernos de História 4. São Paulo, Obelisco, 1967.

BOUlin, J.-Y.; GILBERT, C.; TADDÉI, D. (Orgs.). Le temps de travail. Paris: Syros, 1993.

DAHRENDORF, R. O conflito social moderno: um ensaio sobre a politica da liberdade. Rio de Janeiro: Zahar/Edusp, 1992.

FASE. Pesquisa sobre força de trabalho agrícola em regiões de fronteira. Rio de Janeiro: Acordo Finep/Inan/Fase, 1979. (3ºlatório semestral de pesquisa)

FERREIRA, B.; SILVEIRA, F.G.; GARCIA, R.C. A agricultura familiar e o Pronaf: contexto e perspectivas. In: GASQUES, J.G.; CONCEIÇÃO, J.C.P.R. (Orgs.). Transformações da agricultura e politicas públicas. Brasília: Ipea, 2001. p.479-539.

GAIGER, L.I.G. Culture, religion et praxis socio-politique: la pastorale de libération et le Mouvement de Travailleurs Ruraux Sans-terre au Sud du Brésil. Lovaina: Université Catholique de Louvain, 1991. (tese).
GARCIA, A. A sociologia rural no Brasil: entre escravos do passado e parceiros do futuro. Sociologias, Porto Alegre, PPGS, ano 5, p.154189, jul./dez. 2003.

GASQUES, J.G.; CONCEIÇÃO, J.C.P.R. (Orgs.). Transformações da agricultura e politicas públicas. Brasília: Ipea, 2001.

GEHLEN, I. Identidade estigmatizada e cidadania excluída: a trajetória cabocla. In: ZARTH, P.A. et al. Os caminhos da exclusão social. Ijuí: Unijuí, 1998. p.121-141.

GEHLEN, I.; MÉLO, J.L.B. de. A dinâmica da agricultura no Sul do Brasil: realidade e perspectivas nos anos noventa. São Paulo em Perspectiva, São Paulo, Fundação Seade, v.11, n.2, p.99-108, abr./ jun.1997.

GOFFMAN, E. Estigma: notas sobre a manipulação da identidade deteriorada. 4. ed. Rio de Janeiro: Guanabara, Koogan, 1988.

GUANZIROLI, C.H.; CARDIM, S.E. (Coord.). Novo retrato da agricultura familiar - o Brasil redescoberto. Brasília: Projeto de Cooperação Técnica Incra/FAO, 2000.

JEAN, B. A forma social da agricultura familiar contemporânea: sobrevivência ou criação da economia moderna. Cadernos de Sociologia, Porto Alegre, PPGS-UFRGS. v.6, p.51-75, 1994.

LEITE, S.; HERÉDIA, B.; MEDEIROS, L.; PALMEIRAS, M.; CINTRÃO, R. (Orgs.). Impactos dos assentamentos - Um estudo sobre o meio rural brasileiro. Brasília: Nead/Unesp, 2004.

LERRER, D. Reforma agrária: os caminhos do impasse. São Paulo: Garçoni, 2003.

MARTINE, G.; GARCIA, R.C. Os impactos sociais da modernização agrícola. São Paulo: Caetés, 1987.

MARTINI, M.L.F. Sobre o caboclo-camponês: um gaúcho a pé. Dissertação (Mestrado) - UFRGS/PPGS, Porto Alegre, 1993.

NEUFVILE, S. Travail et loisirs, histoire d'un divorse. Alternatives economiques, Paris, n.139, p.46, jul./ago. 1996.

PNUD/IPEA/FJJ/IBGE. Atlas do desenvolvimento humano no Brasil. 1998.

VAINER,C.B.; AZEVEDO,V.R. de. Classificar, selecionar, localizar: notas sobre a questão racial e a migração. Rio de Janeiro: PUR/ UFRJ [s.d.].

ZARTH, P.A. História agrária do Planalto gaúcho: 1850-1920. Ijuí: Unijuí, 1997.

Ivaldo Gehlen: Professor do Departamento de Sociologia e dos Programas de Pós-Graduação de Sociologia, de Desenvolvimento Rural e de Agronegócios da UFRGS - Porto Alegre (ivaldo@ufrgs.br). 